\title{
Book review - The Motional Improvisation of Al Wunder
}

\section{Tamarisk Glogauer}

Rhodes University, South Africa

\section{The Motional Improvisation of Al}

Wunder, by H.R. Elliott

Routledge, 2021. ix + 175pp.

The Motional Improvisation of Al Wunder by $\mathrm{H}$. R. Elliott is an exploration of the improvisational movement pedagogy of Melbourne-based performer and movement instructor Al Wunder. The book introduces the reader to Wunder through a variety of personal recollections, interviews with past students, and biographical details of his career and dance lineage.

This book begins with an acknowledgment by the author that there is already something nostalgic about the idea of live improvisation and performance in a world still trying to understand and come to terms with the impact of Covid-19. And indeed one can't but help notice a faint feeling of nostalgia as Elliott provides detailed recollections of her time spent as a student of Wunder.

At the end of the introduction to this book there is a short section that I find particularly remarkable. This is entitled 'a unique lexicon' and plunges the reader abruptly into Wunder's world by providing a list of the terms and phrases that Wunder uses to describe his own practice. The selection of sometimes unexpected definitions introduce a host of terms that illustrate the unique teaching practice that is detailed in later chapters as well as sparking, for me, a curiosity about the world of Wunder.

Much of the first chapter of this book, titled 'Creative geneaologies' is dedicated to tracing a performance lineage for Wunder, with a specific focus on Wunder's dance mentor Alwin Nikolais. The section detailing the influence that Nikolais had on Wunder is headed in the same way that Elliott chooses to head her own introduction to the work of Wunder immediately alluding to the all important connective lineage of improvised movement and dance that Wunder is part 
of. The theme of movement lineage through mentors is echoed throughout the book as Elliott focuses both on the dancers and improvisors who came before Wunder, and on the students of Wunder, herself included, who carry lessons learnt from the motional improvisor into the future.

In the first few chapters we are given an in-depth look at the improvisational style of Wunder and the specific language and tasks with which he shapes his work. Elliott opens the door into a workshop with Wunder through her own notes and embodied memory of his 'theatre of the ordinary'. Wunder is depicted as a slightly mysterious figure who teaches and guides students from the side of the dance space - speaking seldom and creating a percussive score on his Hum Drum. There is an emphasis on the inclusivity of Wunder's teaching methods that favour experimental movement at any level over the exclusivity of the highly trained dancing body. Wunder's teaching style is about constructing firm but interpretable boundaries and areas of work/play for his students and then mostly distancing himself in an effort to destabilise the student/teacher hierarchy. In this way, the students are allowed to take more control over schooling themselves under the guidance of Wunder's experienced mentorship.

At the end of a class or workshop with Wunder, Elliott describes a part of class known as 'total improvisation'. This section is completely unscored and without instruction and asks students to perform an improvised dance for the rest of the class. The only structure in this final part of the class is a time constraint - starting at five minutes and moving up to thirty for those who have undergone a lengthy period of training. Elliott writes of the vulnerability of these solo performances and also of how energised and awakened students felt after emerging from a session of total improvisation.

Among the many phrases and focus words that define and direct the teaching of Wunder, is the titular term 'motional'. Understanding this word, for me, is key to unlocking an understanding of much of the pedagogical tools that Elliott delves into. For Wunder, this term encapsulates a strong awareness of body and experience of movement. Wunder's use of the word 'motional' emphasises the importance of acute physical and mental presence in his practice - an awareness cultivated through feeling the body in time and space.

Being aware of the body, and more specifically being aware of the feeling of 
movement and stillness in the body, and play.

reoccurs throughout the discussions of Wunder's work and teaching. While Elliott does not deal directly with mindfulness as a concept, themes of hyper-awareness of joints and articulations, of coming to feel the passage of time in the body, of stillness, and of being fully present before an audience resonates undeniably with mindfulness in performance. Wunder requires that his students be totally aware and present in the moment in order to participate in motional improvisation.

Later chapters delve into Wunder's use of the 'Hum Drum', into the shifts in place and style that bought him eventually to Melbourne, his notion of positive feedback, modes of being in performance, and ways of entertaining an audience, among other subjects. The book is richly furnished with detail that invites the reader to consider Wunder's unique motional improvisation and the ripples that continue to fan out from his dance lineage. The Motional Improvisation of Al Wunder ends with a warm depiction of Wunder at 75 still moving, improvising and creating with intention, playfulness, and presence. Elliott's book will likely prove a valuable resource for those interested in dance improvisation and ways of engaging the body in creative and present performance 